\title{
Preparation and properties of cellulose membranes with graphene oxide addition
}

\author{
Beata Fryczkowska*, Kamil Wiechniak \\ University of Bielsko-Biala, Faculty of Materials, Civil and Environmental Engineering, Institute of Textile Engineering \\ and Polymer Materials, Willowa 2, 43-309 Bielsko-Biala, Poland, \\ "Corresponding author: e-mail: bfryczkowska@ath.bielsko.pl
}

\begin{abstract}
The paper presents results of research on the preparation of cellulose membranes with graphite oxide addition (GO/CEL). Initially, a cellulose (CEL) solution in 1-ethyl-3-methylimidazole acetate (EMIMAc) was obtained, to which graphene oxide (GO) dispersed in N,N-dimethylformamide (DMF) was added. From this solution, composite membranes were formed using phase inversion method. It was observed that the GO addition influences the physico-chemical properties of GO/CEL composite membranes, resulting in an increase in their mass per unit area, thickness and density, and a decrease in sorption properties. In addition, the study of transport properties has shown that GO/CEL membranes do not absorb BSA particles on their surface, which prevents the unfavorable phenomenon of fouling. An important feature of the obtained membranes is the specific permeate flux which reaches high values $\left(\sim 124 \mathrm{~L} / \mathrm{m}^{2} \times \mathrm{h}\right)$ at $3.8 \%$ of the GO addition to the cellulose matrix.
\end{abstract}

Keywords: cellulose, ionic liquid, graphene oxide, membranes, transport properties.

\section{INTRODUCTION}

Cellulose is one of the most widespread, inexpensive and biodegradable polymers used in the textile, chemical, pharmaceutical, construction and energy industries ${ }^{1-2}$. Chemically, cellulose is a linear polymer linked with stable glycosidic bonds, accompanied by intra- and intermolecular hydrogen bonds ${ }^{3-4}$. The presence of this type of bonds, as well as the presence of crystalline areas in cellulose makes this polymer insoluble in water and in most solvents ${ }^{5-6}$. $\mathrm{NaOH} / \mathrm{CS}_{2}, \mathrm{NMMO} / \mathrm{H}_{2} \mathrm{O}, \mathrm{LiCl} / \mathrm{DMAc}$, $\mathrm{DMSO} / \mathrm{TBAF}$ and ionic liquids are used for the processing of cellulose ${ }^{7}$. Regenerated cellulose is used for the production of fibers, films, membranes, hydrogels and aerosols, microspheres and beads?

A new group of solvents are ionic liquids, often referred to as "green" solvents ${ }^{8}$. Due to the biodegradability and low toxicity" they are considered to be environmentally friendly solvents, which may eventually replace the traditional systems that are capable of dissolving cellulose $^{4,9-10}$. The cellulose dissolved in ionic liquids can be easily precipitated using polar solvents (water, ethyl alcohol, acetone, methylene chloride, acetonitrile ${ }^{4}$ to obtain "flocs", fibers or membranes ${ }^{11-13}$. The regenerated cellulose thus obtained is less crystalline and more porous than native cellulose $\mathrm{e}^{13-17}$.

An interesting and modern material is graphene (RG) and graphite oxide (GO), which are synthesized and used for the production of polymer composites by the authors of the article ${ }^{18}$. GO has a lot of different oxygencontaining functional groups, such as epoxy, hydroxyl, carbonyl, carboxyl1 ${ }^{19}$. Oxygen groups give hydrophilic properties to GO, making it easy to form stable aqueous dispersions ${ }^{20-21}$. GO can also be dispersed in organic solvents such as N,N-dimethylformamide, N-methyl-2-pyrrolidone, tetrahydrofuran and ethylene glycol $^{22}$. Graphene oxide has sorption properties, which is why it is used to remove heavy metals ${ }^{23}$. In addition, it has antimicrobial properties ${ }^{24}$, which extends its use in water and wastewater treatment processes. GO, along with carbon nanotubes ${ }^{23-26}$ and graphene $e^{27-29}$ is used in membranes. It allows obtaining thin, monolayer films $\mathrm{s}^{30-33}$ which can be used for desalination and purification ${ }^{27-28,34-35}$ as well as membrane distillation ${ }^{38}$. Graphene oxide is also used as a component of composite materials. Literature provides examples of preparation of $\mathrm{GO} /$ cellulose composite in the form of granules. Zhang et al. described the method of obtaining GO-containing microbeads in $\mathrm{NaOH}$ and urea solution, which were coagulated in the presence of $\mathrm{HNO}_{3}{ }^{39}$. Another team obtained such a composite during the synthesis of cellulose by bacteria ${ }^{40}$. Nanocomposite aerogels, on the other hand, were obtained from bamboo fibers dissolved in a NaOH/PEG mixture to which water-dispersed GO was added ${ }^{41}$. Rui-Hong et al. obtained hydrogel by introducing $\mathrm{NaOH}$ and urea and cellulose into the aqueous dispersion of $\mathrm{GO}$, followed by mixing it with PVA solution ${ }^{42}$. Liu et al. obtained cellulose composite membranes by filtration of GO solution on pure cellulose membrane ${ }^{43}$. The paper-making method was used to obtain paper with GO addition in the presence of polyacrylamide ${ }^{44}$. Yang et al. mixed the grinded bacterial cellulose with GO dispersion and formed a composite film ${ }^{45}$. Other researchers mixed subhydrolized microcrystalline cellulose in the form of suspension with GO dispersion and dried the resulting mixture $^{46}$. Kim et al. obtained a $\mathrm{GO} /$ cellulose membrane by dissolving $\mathrm{GO}$ and cellulose in $\mathrm{NMMO}^{47}$. The layerby-layer method (LbL) was used to apply a cellulose solution in ionic liquid $[\mathrm{Bmim}] \mathrm{Cl}$ on a glass plate, dry it and coat with a GO dispersion ${ }^{48}$.

This paper presents a method of obtaining cellulose membranes with $\mathrm{GO}$ addition that has not been described in the literature. 1-ethyl-3-methylimidazole acetate (EMIMAc), which is a room-temperature ionic liquid, as recommended by the literature to dissolve the biopolymer ${ }^{49}$ was used to prepare the cellulose solution. A method has been developed to combine a solution of cellulose dissolved in the ionic liquid with graphene oxide dispersed in N,N-dimethylformamide. From this homogeneous solution, composite membranes were formed by phase inversion method, and coagulated in distilled water. It was observed that the amount of graphene 
oxide added to the cellulose solution in the ionic liquid influences the physico-chemical and transport properties of the resulting membranes.

\section{EXPERIMENTAL}

\section{Material}

Cellulose (long fibers), ionic liquid: 1-ethyl-3-methylimidazolium acetate (EMIMAc), graphite powder $<20$ $\mu \mathrm{m}$, bovine serum albumin (BSA) $(\mathrm{Mw}=\sim 66 \mathrm{kDa})$ were purchased from Sigma-Aldrich. $\mathrm{NaNO}_{3}, 98 \% \mathrm{H}_{2} \mathrm{SO}_{4}$, $\mathrm{KMnO}_{4}, 30 \% \mathrm{H}_{2} \mathrm{O}_{2}, \mathrm{~N}$, N-dimetyloformamid (DMF), anhydrous $\mathrm{FeCl}_{3}$ and methylene blue (MB) were purchased from Avantor Performance Materials Poland S.A.

\section{Equipment}

Thickness of the membranes was measured with ELMETRON MG-1 thickness gauge. SARTORIUS CP224S-0CE analytical balance with a reading accuracy of $0.0001 \mathrm{~g}$ was used with for mass measurements. Daewoo laboratory microwave oven with $114 \mathrm{~W}$ heating power and Inter Sonic IS-1 ultrasonic washer, with ultrasonic frequency of $35 \mathrm{kH}$ were used for the preparation of the membrane-forming solution. Viscosity measurements were made using Myr V2-L rotary viscometer equipped with L3 and L2 spindles and a temperature sensor. Transport properties of the obtained membranes were tested using Millipore's Amicon 8400 ultrafiltration cell with a capacity of $350 \mathrm{~cm}^{3}$ and a membrane diameter of $7.6 \mathrm{~cm}$, equipped with equalizing tank with a capacity of $800 \mathrm{~cm}^{3}$ and a stirrer. The UV-Vis Perkin Elmer Lambda 35 spectrophotometer was used to determine the concentration of the test solutions $\left(\mathrm{FeCl}_{3}, \mathrm{MB}\right.$ and BSA), and the wavelengths for the respective solutions were: $\mathrm{FeCl}_{3}(\lambda=260 \mathrm{~nm}), \mathrm{MB}(\lambda=662 \mathrm{~nm})$ and BSA $(\lambda=280 \mathrm{~nm})$.

\section{Synthesis of graphene oxide}

Graphene oxide was obtained according to modified Hummers method ${ }^{50}$. The process to obtain GO is the same as described in our previous paper ${ }^{51} .1 \mathrm{~g}$ of $\mathrm{NaNO}_{3}, 46 \mathrm{~cm}^{3}$ of $\mathrm{H}_{2} \mathrm{SO}_{4}$ and $2 \mathrm{~g}$ of graphite powder were introduced in a flask placed in an ice bath and stirred vigorously for 30 minutes. Then, portionwise, $6 \mathrm{~g}$ of $\mathrm{KMnO}_{4}$ was added, so that the temperature of the system did not exceed $20^{\circ} \mathrm{C}$. After adding all $\mathrm{KMnO}_{4}$ and waiting for five minutes, the reaction mixture was heated to $35^{\circ} \mathrm{C}$. The reaction mixture was stirred for 4 $\mathrm{h}$ at this temperature and then slowly $92 \mathrm{~cm}^{3}$ of distilled water was added. Excess $\mathrm{KMnO}_{4}$ was removed from the reaction mixture by introducing a mixture of $80 \mathrm{~cm}^{3}$ of distilled water and $50 \mathrm{~cm}^{3}$ of $3 \% \mathrm{H}_{2} \mathrm{O}_{2}$. Finally, the obtained graphene oxide was centrifuged and washed several times with distilled water until neutralized $(\mathrm{pH} 7)$. Wet graphene oxide was dried in a laboratory drier at $60^{\circ} \mathrm{C}$ to obtain a brown precipitate which was then dispersed in DMF on an ultrasonic bath to obtain a $3.7 \% \mathrm{GO} /$ DMF dispersion.

Preparation of cellulose solution and GO/CEL solution Initially, a $5 \%$ solution of cellulose in the ionic liquid - 1-ethyl-3-methylimidazolium acetate (EMIMAc) was prepared. The mixture of cellulose and EMIMAc was thoroughly mixed and then heated in a microwave oven in intervals of $3 \times 5$ seconds, taking care that the temperature of the mixture did not exceed approx. $40^{\circ} \mathrm{C}$. The resulting cellulose solutions wre left for 24 hours to deaerate. In order to prepare solutions for forming GO/CEL composite membranes, adequate amounts of cellulose and ionic liquid were first weighed (Table 1) and cellulose solutions were prepared as described above. Appropriate amounts of 3.7\% GO/DMF solution (Table 1) were then added to the cellulose solutions, thoroughly mixed and sonicated for 15 minutes. The obtained GO/CEL solutions were allowed to deaerate for 24 hours. Then, using Myr V2-L rotary viscosity gauge, the viscosities of the membrane-forming solutions were measured at $25^{\circ} \mathrm{C}$ (Table 1), demonstrating that the viscosity of the GO+DMF/CEL+EMIMAc solution dramatically decreases with the increase in the graphene oxide concentration.

\section{Membrane forming}

Cellulose membranes were prepared using phase inversion method. For this purpose, pre-prepared solutions were poured on a level, clean glass plate. Then a polymeric film was formed using casting knife with an adjustable thickness fixed at $0.2 \mathrm{~mm}$. Finally, it was rapidly coagulated in distilled water at room temperature until the membrane detached from the glass. Precipitated membranes were air dried. In our laboratory, a thin layer of polyester fabric followed by layers of tissue paper are used to separate the cellulose membranes. This prevents the cellulose from sticking to the filter paper and facilitates the drying of the cellulose. Membranes were dried under glass plate load.

\section{General characterization}

At the beginning, using the analytical balance, $1 \times 1$ $\mathrm{cm}$ membrane samples were weighed and their thickness was measured with the electronic thickness gauge. The mass per unit area $\left(\mathrm{W}_{\mathrm{s}}\right)\left(\mathrm{g} / \mathrm{cm}^{2}\right)$ and the density $\left(\mathrm{d}_{\mathrm{m}}\right)$ of the membranes $\left(\mathrm{g} / \mathrm{cm}^{3}\right)$ were calculated using the following formulas $(1,2)$ :

$$
\begin{aligned}
& \mathrm{W}_{\mathrm{s}}=\frac{\mathrm{w}}{\mathrm{s}} \\
& \mathrm{d}_{\mathrm{m}}=\frac{\mathrm{w}}{\mathrm{s} \times 1}
\end{aligned}
$$

where: w - the weight of a membrane with an area of $1 \mathrm{~cm}^{2}$, s-membrane surface area $\left[\mathrm{cm}^{2}\right], 1-m e m b r a n e$

\begin{tabular}{|c|c|c|c|c|c|c|c|}
\hline Membrane designation & "0" & A & B & C & $\mathrm{D}$ & $\mathrm{E}$ & $\mathrm{F}$ \\
\hline The amount of $3.7 \%$ GO/DMF solution [g] & 0 & 0.135 & 0.34 & 0.67 & 1.35 & 6.76 & 13.5 \\
\hline The amount of CEL [g] & 2.5 & 2.5 & 2.5 & 2.5 & 2.5 & 2.5 & 2.5 \\
\hline The amount of EMIMAC [g] & 47.5 & 47.4 & 47.2 & 46.8 & 46.2 & 40.1 & 34.0 \\
\hline W/w conc. of GO [\%] & 0 & 0.5 & 1.0 & 4.0 & 3.8 & 16.7 & 28.6 \\
\hline W/w conc. of CEL [\%] & 100 & 99.5 & 99.0 & 98.0 & 96.2 & 83.3 & 71.4 \\
\hline Viscosity [mPaxs] & 14450 & 8970 & 6420 & 4670 & 3120 & 820 & 170 \\
\hline
\end{tabular}

Table 1. The composition and viscosity of the solutions for the preparation of membranes 
thickness $[\mathrm{cm}]$.

The sorption of water $(U)$ was measured in such a way that the membrane samples of $1 \times 1 \mathrm{~cm}$ were weighed on an analytical balance with an accuracy of $0.0001 \mathrm{~g}$, and then inserted into distilled water for 10 seconds. Then they were blotted on filter paper and weighed again in the wet state. The sorption of water (U) was calculated according to formula (3):

$\mathrm{U}=\frac{\mathrm{W}_{\mathrm{w}}-\mathrm{W}_{\mathrm{d}}}{\mathrm{W}_{\mathrm{d}}} \times 100 \%$

where: $\mathrm{W}_{\mathrm{w}}-$ mass of wet membranes [g]; $\mathrm{W}_{\mathrm{d}}-$ mass of dry membranes $[\mathrm{g}]$

The porosity of the membranes $(\varepsilon)$, which is defined as the ratio of pore volume to the volume of the membrane, was calculated using the following formula ${ }^{52}(4)$ :

$\varepsilon=\frac{\left(\mathrm{W}_{\mathrm{w}}-\mathrm{W}_{\mathrm{d}}\right) / \mathrm{dw}}{\left(\mathrm{W}_{\mathrm{w}}-\mathrm{W}_{\mathrm{d}}\right) / \mathrm{d}_{\mathrm{w}}+\mathrm{W}_{\mathrm{d}} / \mathrm{d}_{\mathrm{p}}} \times 100 \%$

where: $\mathrm{w}_{\mathrm{w}}-$ wet sample weight $(\mathrm{g}) ; \mathrm{w}_{\mathrm{d}}-$ dry sample weight $(\mathrm{g}) ; \mathrm{d}_{\mathrm{w}}-$ density of water $\left(0.998 \mathrm{~g} / \mathrm{cm}^{3}\right) ; \mathrm{d}_{\mathrm{p}}$ - polymer density $\left(1.55 \mathrm{~g} / \mathrm{cm}^{3}\right)^{53}$.

In addition, the sorption properties of the membranes were compared to the following standard solutions: 0.1 $\mathrm{g} / \mathrm{dm}^{3} \mathrm{FeCl}_{3}, 0.00005 \mathrm{~mol} / \mathrm{dm}^{3} \mathrm{MB}$ and $1.0 \mathrm{~g} / \mathrm{dm}^{3}$ BSA. $1 \mathrm{x} 1 \mathrm{~cm}$ samples of the membranes were weighed on an analytical balance with an accuracy of $0.0001 \mathrm{~g}$ and then introduced into flasks containing $10 \mathrm{~cm}^{3}$ of the test solution. The flasks were sealed with a stopper and left for 24 hours. Subsequently, the membrane samples were removed and the absorbance of the test solutions was measured using UV-Vis spectrophotometer. Based on the calibration curve, the concentrations of the solutions in each sample were calculated. Sorption of individual compounds (C) was calculated using the following formula (5):

$\mathrm{C}=\frac{\mathrm{C}_{1}-\mathrm{C}_{2}}{\mathrm{C}_{1}} \times 100 \%$

where: $\mathrm{C}_{1}$ - initial concentration of the test solution; $\mathrm{C}_{2}$ - concentration of solution after examining sorption properties.

\section{Transport properties}

Transport properties were studied in an ultrafiltration cell. For this purpose, dry membranes were introduced into the cell, filled with distilled water and left for 1 hour to prevent cracking during measurements. Then they were treated with distilled water for 2 hours under a pressure of $0.2 \mathrm{MPa}$ (which is beneficial for the membrane stability). Tests were carried out at a working pressure of $0.1 ; 0.15$ and $0.2 \mathrm{MPa}$. Permeate flux (Jv) was calculated using the following formula (6):

$\mathrm{J}_{\mathrm{v}}=\frac{\mathrm{Q}}{\mathrm{A} \times \mathrm{t}}$

where: $\mathrm{Jv}$ is water flux $\left[\mathrm{L} / \mathrm{m}^{2} \times \mathrm{h}\right], \mathrm{Q}$ is the volume of water permeate $[\mathrm{L}], \mathrm{A}$ is the effective membrane area $\left[\mathrm{m}^{2}\right]$, and $\mathrm{t}$ is the permeation time $[\mathrm{h}]$.

Additionally, the transport properties of the membranes were investigated using solutions of compounds with highly varying sizes. For this purpose, reference solutions with the following concentrations were prepared: 0.1 $\mathrm{g} / \mathrm{dm}^{3} \mathrm{FeCl}_{3}, 0.0001 \mathrm{~mol} / \mathrm{dm}^{3} \mathrm{MB}$ and $1.0 \mathrm{~g} / \mathrm{dm}^{3}$ BSA. Then, $200 \mathrm{~cm}^{3}$ of successive standard solutions were added to the ultrafiltration cell with the test membrane and the stirrer (stirring of the feed solution allows to avoid fouling). The permeation process was carried out at a working pressure of $0.2 \mathrm{MPa}$ and $20 \mathrm{~cm}^{3}$ doses of permeate were tapped, measuring simultaneously the time of the permeate discharge from the test tank. Permeate flux (Jv) was calculated using the formula (6), assuming that in this case $\mathrm{Q}$ is the permeate volume (specific test solution).

\section{RESEARCH RESULTS AND THEIR ANALYSIS}

\section{Characteristics of GO}

Graphene oxide, which was used to obtain composite GO/PAN membranes was studied using X-ray diffraction, DSC thermal gravimetric analysis and FTIR spectroscopy. The results were similar to the ones obtained in our earlier publication ${ }^{51}$.

\section{Physicochemical properties}

The scope of research in the described paper are GO/ CEL membranes produced by phase inversion through the polymer coagulation in a non-solvent (wet method). Combining GO with cellulose in the form of a homogeneous solution may create the possibility of obtaining a durable composite, not described in literature, in which the components are linked together by hydrogen bonds, covalent bonds and electrostatic interactions ${ }^{41}, 48$. The article presents how the GO concentration affects the structure and physicochemical properties (thickness, mass per unit area, density, sorption, porosity) of the resulting GO/CEL composite membranes.

Studies (Fig. 1a) have shown that even a small GO addition influences the membrane coagulation process, resulting in an increase in the mass per unit area of GO/CEL composite membranes. The mass per surface area for pure cellulose membrane is $0.0026 \mathrm{~g} / \mathrm{cm}^{2}$. For $\mathrm{GO} / \mathrm{CEL}$ composite membranes, the mass per surface area increases by $170 \sim 330 \%$. Membrane B, containing $1 \% \mathrm{w} / \mathrm{w}$ of $\mathrm{GO}$, is characterized by the largest mass per surface area value $\left(0.0082 \mathrm{~g} / \mathrm{cm}^{2}\right)$. On the other hand, for $\mathrm{E}$ and $\mathrm{F}$ membranes, over $50 \%$ increase in the mass is observed. Thus, it can be assumed that hydrogen bonds are created between cellulose and graphene oxide preventing the cellulose from being washed out during membrane coagulation. Tang et al. proposed a pattern for the formation of such bonds ${ }^{48}$. Graphite oxide affects not only the mass per surface area of the resulting membranes, but also their thickness. In Figure $1 \mathrm{~b}$ it is observed that the addition of cellulose of up to $0.5,1$ and $2 \%$ increases the thickness of the resulting membranes 3 3.5 times. On the other hand, in the case of $\mathrm{D}$ and $\mathrm{E}$ membranes their thickness increase only by $50 \%$. For membrane $\mathrm{F}$ (containing almost $30 \%$ of GO) the large amount of graphene oxide actually does not affect its thickness. The results show that a small GO addition influences the coagulation process of membranes A, B and $\mathrm{C}$, resulting in high thickness and therefore porosity of the membranes obtained. By analyzing the density results of the membranes (Fig. 1c), the lowest density 

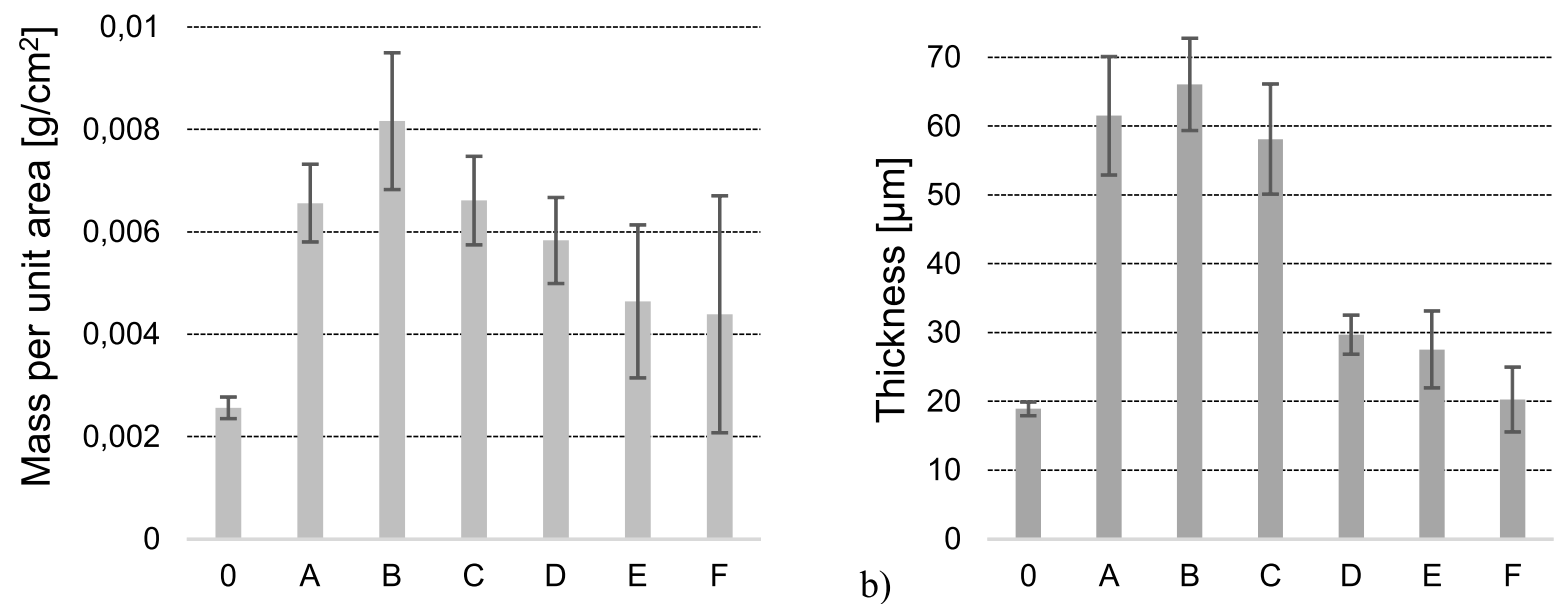

a)

3

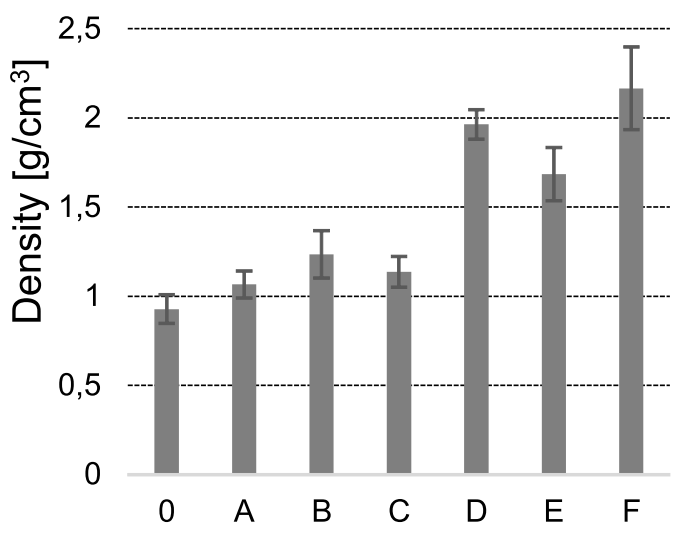

Figure 1. Effect of GO addition on: a) the mass per unit area; b) the thickness; c) the density of membranes

is observed for membrane " 0 " $\left(0.93 \mathrm{~g} / \mathrm{cm}^{3}\right)$ membrane, which is characterized by lower density than the initial cellulose. Such a result may indicate the amorphous structure of the resulting membrane. All GO/CEL composite membranes have a higher density than pure cellulose membranes. The density of membranes A, B and $\mathrm{C}$ is in the range of $1.07 \sim 1.24 \mathrm{~g} / \mathrm{cm}^{3}$. And membranes containing more than $4 \% \mathrm{GO}$ are characterized by high density values $\left(1.7 \sim 2.3 \mathrm{~g} / \mathrm{cm}^{3}\right)$, which results from their high mass per surface area and low thickness. The obtained results confirm that GO addition to the cellulose matrix has a strong influence on the coagulation of composite membranes.

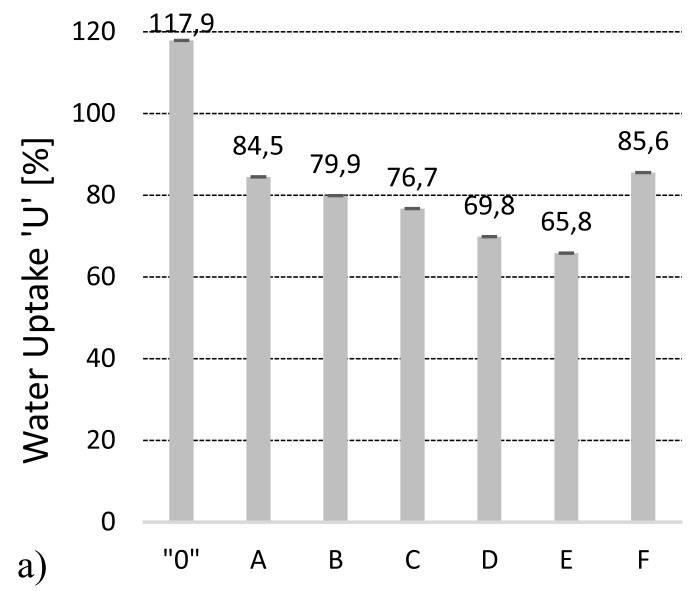

Cellulose is a hydrophilic polymer, as confirmed by cellulose membrane testing. Water sorption studies (Fig. 2a) have shown that membrane " 0 " adsorbs water best out of all membranes obtained $(\sim 118 \%)$. The addition of graphite oxide in GO/CEL composite membranes lowers the water sorption, which decreases with the increase in GO concentration in the membrane and is $\sim 86 \%$ (for membrane $\mathrm{A}$ ), $\sim 80 \%$ (for membrane B), $\sim 77 \%$ (for membrane C) $\sim 70 \%$ (for membrane D), $\sim 66 \%$ (for membrane E). For membrane F, the water sorption is increased to $\sim 86 \%$, which can result from the high content of hydrophilic GO (almost 30\%) in the composite membrane. Studies have shown that

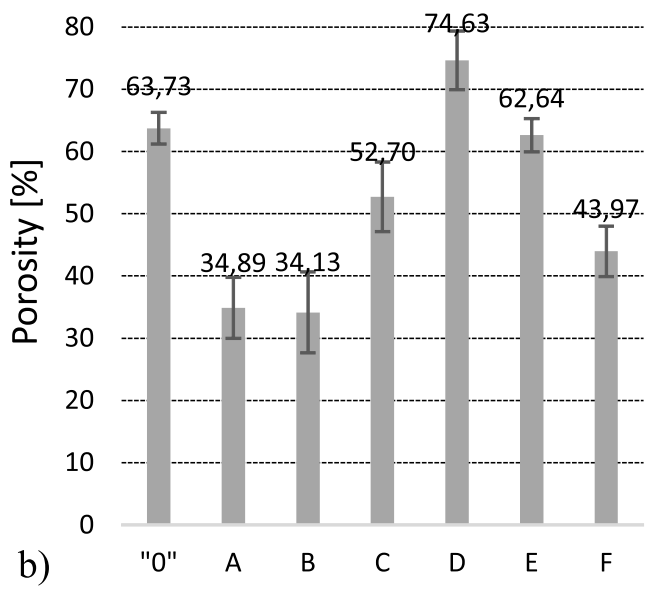

Figure 2. Effect of GO addition on: a) the sorption of water and porosity of the membranes 
graphene oxide, which has such functional groups as epoxy, hydroxyl, carbonyl, carboxy $1^{19}$ can form hydrogen bonds with cellulose hydroxyl groups ${ }^{46}, 48$. As a result of these effects, the number of groups responsible for the hydrophilic properties of the GO/CEL composite is reduced, resulting in the reduction of water sorption. The porosity calculations (Fig. 2b) showed that cellulose membranes " 0 " have a porosity of $\sim 64 \%$, which, considering their low mass per surface area, is a good result. For GO/CEL composite membranes, a porosity decrease of $45 \%$ is observed for membranes $\mathrm{A}$ and $\mathrm{B}$ relative to pure cellulose. These membranes (A and B) are characterized simultaneously by high thickness and low density, which may indicate that during the coagulation the structures characteristic for compact membranes were formed. A similar conclusion can be drawn for the membrane $\mathrm{C}$, whose porosity is slightly higher and amounts to $\sim 53 \%$. For membranes D, E and $\mathrm{F}$ the porosity values are $74.63 ; 62.64$ and $43.97 \%$, respectively, which results from their low thickness, high density, and indicates the formation of porous structures in the obtained membranes.

The sorption studies (Fig. 3) indicate that methylene blue, which is a direct dye for cellulose, is well adsorbed on the membranes, with sorption on membrane "0" diaphragm being the lowest ( $62 \%)$. For GO/CEL composite membranes, $\mathrm{MB}$ sorption increases with the amount of GO addition up to $90 \sim 97 \%$. The results show that the GO addition facilitates the adsorption of the dye on the composite membranes. Literature reports indicate that bonds can be formed between the negatively charged dye and $\mathrm{GO}^{43}$, which may affect dye retention in the membrane, as confirmed by the results obtained in our experiment. Zhang et al. ${ }^{39}$ used GO caged in cellulose microbeads to remove another dye - malachite green - from aqueous solutions. Upon contact with aqueous solution of $\mathrm{Fe}^{3+}$ iron ions with the membranes, its amount adsorbed on pure cellulose membrane as compared to $\mathrm{MB}$ is higher and amounts to $\sim 76 \%$. In the case of GO/CEL composite membranes, on the other hand, the amount of $\mathrm{FeCl}_{3}$ adsorbed on membranes A and B is slightly lower $(\sim 71 \%$ and $\sim 74 \%$, respectively) compared to membrane "0". The increase in the amount of GO addition in membranes $\mathrm{C}, \mathrm{D}, \mathrm{E}$ and $\mathrm{F}$ results in an increase in adsorption of
$\mathrm{Fe}^{3+}$ ions at the level of $87 \sim 91 \%$. The results of $\mathrm{FeCl}_{3}$ sorption for $\mathrm{GO} / \mathrm{CEL}$ composite membranes indicate lower values than those obtained for dye. Liu et al. ${ }^{43}$ explain the mechanism of retention of positively charged particles on membranes containing GO, which, as they believe, results from electrostatic interactions. In the case of metal cations, it is also possible to find coordination links between functional groups present in cellulose and in graphene oxide. Examination of the sorption properties of membranes using BSA indicates that the adsorption of a compound with such a high molecular weight is very low and is in the range of $1.5 \sim 11 \%$. The lowest adsorption values were recorded for pure cellulose membranes, which may indicate no interaction between the membrane and BSA. In the case of GO/CEL composite membranes, it can be observed that the GO addition improves, though slightly, the sorption of these membranes with respect to the protein. The conducted experiments allow to suppose that during the membrane process using $\mathrm{FeCl}_{3}$ and $\mathrm{MB}$ the first step is the adsorption of the test compounds on the membranes and only then their separation. In the case of BSA, on the other hand, it is expected that the protein molecules will not be adsorbed on the membranes and probably will not impede the permeation process.

\section{Transport properties}

An important parameter determining the transport properties of membranes is the specific permeate flux (Fig. 4). The pure cellulose membranes obtained in the experiment were characterized by low flux: $2.3 ; 2.9$ and $4.2\left[\mathrm{~L} / \mathrm{m}^{2} \times \mathrm{h}\right]$ respectively for working pressures of $0.1 ; 0.15$ and $0.2 \mathrm{MPa}$. The GO addition significantly influences the transport properties of the GO/CEL composite membranes, resulting in an increase in the specific permeate flux values. A $0.5 \%$ GO addition to cellulose increases the specific permeate flux nearly 3 times. While the addition of $1 \%$ of GO in the composite membrane increases its flux more than 4 times. For other GO/CEL composite membranes, the increase in the specific permeate flux is many times higher. The $2 \%$ addition of GO in the cellulose membrane causes a 15-fold increase in flux through the membrane. The highest values of specific permeate flux are characteristic of membrane D and amount to 50.0; 83.6 and 123.9 [L/

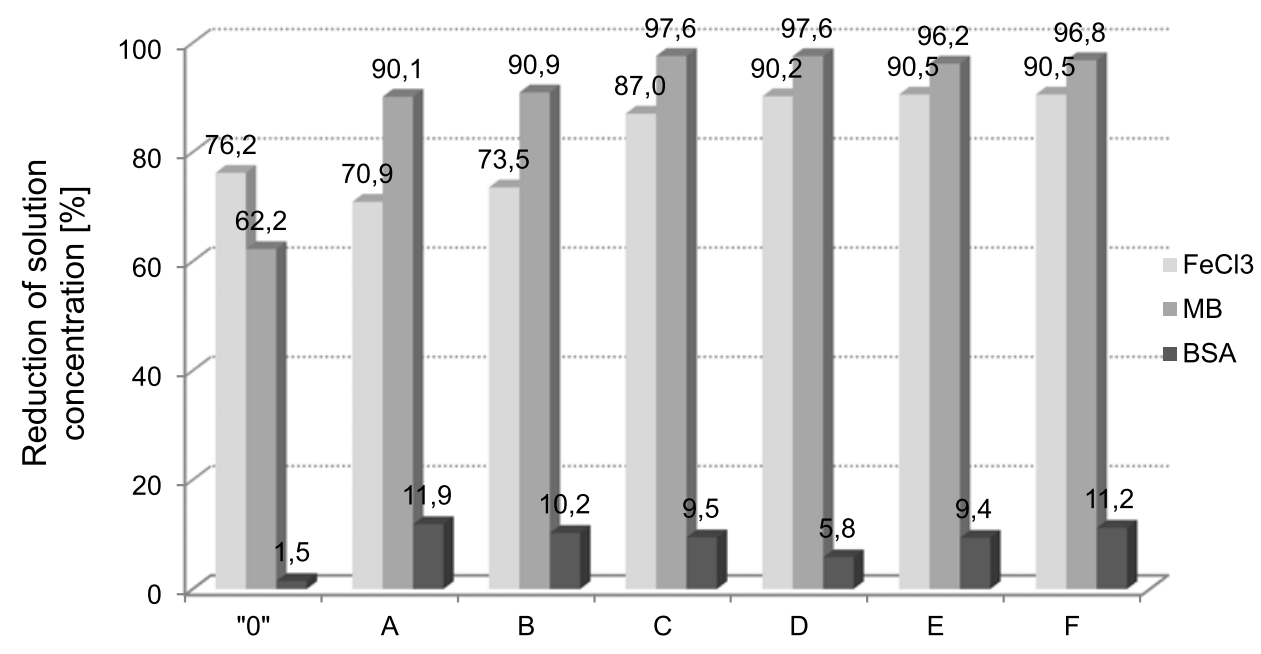

Figure 3. Sorption properties of membranes with solutions containing $\mathrm{FeCl}_{3}, \mathrm{MB}, \mathrm{BSA}$ 


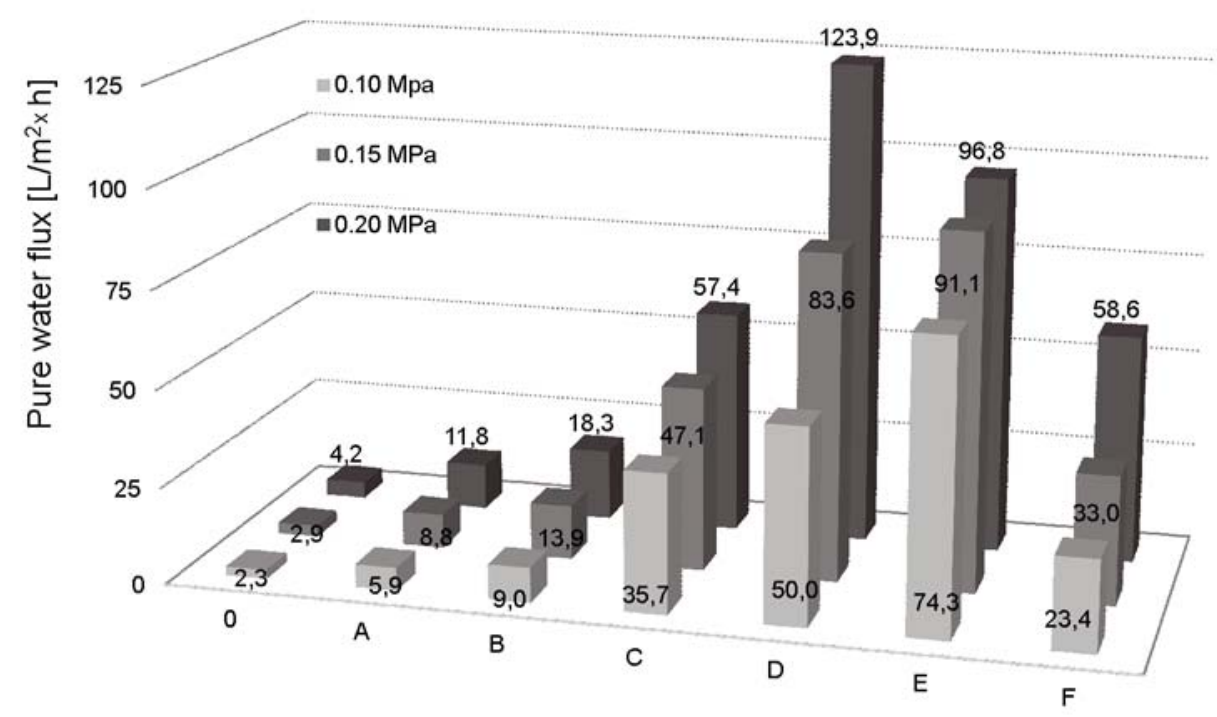

Figure 4. Specific permeate flux for GO/CEL composite membranes and pure cellulose membranes

$\left.\mathrm{m}^{2} \times \mathrm{h}\right]$ respectively for working pressures of $0.1 ; 0.15$ and $0.2 \mathrm{MPa}$. It was also observed that the adding massive quantities of $\mathrm{GO}$ to cellulose membranes impairs the flux through the membranes. The values of the specific permeate flux for membrane $\mathrm{E}$ are 74.3 ; 91.1 and 96.8 $\left[\mathrm{L} / \mathrm{m}^{2} \times \mathrm{h}\right]$ for respective working pressures. On the other hand, for membrane $\mathrm{F}$, the flux decreases to $23.4 ; 33.0$ and $58.6\left[\mathrm{~L} / \mathrm{m}^{2} \times \mathrm{h}\right]$ respectively for working pressures of $0.1 ; 0.15 ; 0.2 \mathrm{MPa}$.

The research allows to conclude that the GO addition in cellulose membranes favorably affects the specific permeate flux, increasing the water flow through the membranes. The best results were obtained for membranes D in which the amount of GO addition was $3.8 \%$. Further increasing of the amount of graphene oxide addition above $4 \%$ results in a decrease in transport properties.

Aqueous solutions of $\mathrm{FeCl}_{3}, \mathrm{MB}$ and $\mathrm{BSA}$ were used to study the transport properties of the obtained membranes (Fig. 5). In the case of the BSA solution, a slight decrease in the specific permeate flux over pure water was observed. Membranes "0", A, B and C were characterized by very similar flux values. The flow of the solution was reduced by about $20 \%$ for composite membranes D, E and F. Such results may indicate that the pure cellulose membrane and the GO/CEL composite membranes do not have the properties that would favor under these conditions (BSA) the unfavorable phenomena of fouling. Other results were obtained using a dye (MB) as the feed. It was found that for the membranes " 0 ", $\mathrm{A}$ and $\mathrm{B}$ there is no drop in the specific permeate flux, although, as shown by previous studies, these membranes adsorb the dye. The result shows no fouling on these membranes. Other composite membranes are characterized by a drop in flow values. For membrane D, which is characterized by the highest value of specific permeate flux, a flow decrease of $60 \%$ was recorded. On the other hand, for membranes $\mathrm{E}$ and $\mathrm{F}$ the flow drop is 70 and $43 \%$, respectively. The results show that the GO addition in excess of $1 \%$ causes the retention of negatively charged dye particles on the membranes. The literature describes the transport properties of membranes in the presence of such dyes as Congon Red, Indigo Carmine, Rodamine B and Methylene Blue ${ }^{\mathbf{4 3}}$. However, comparison of the research described by Liu et al. and our studies

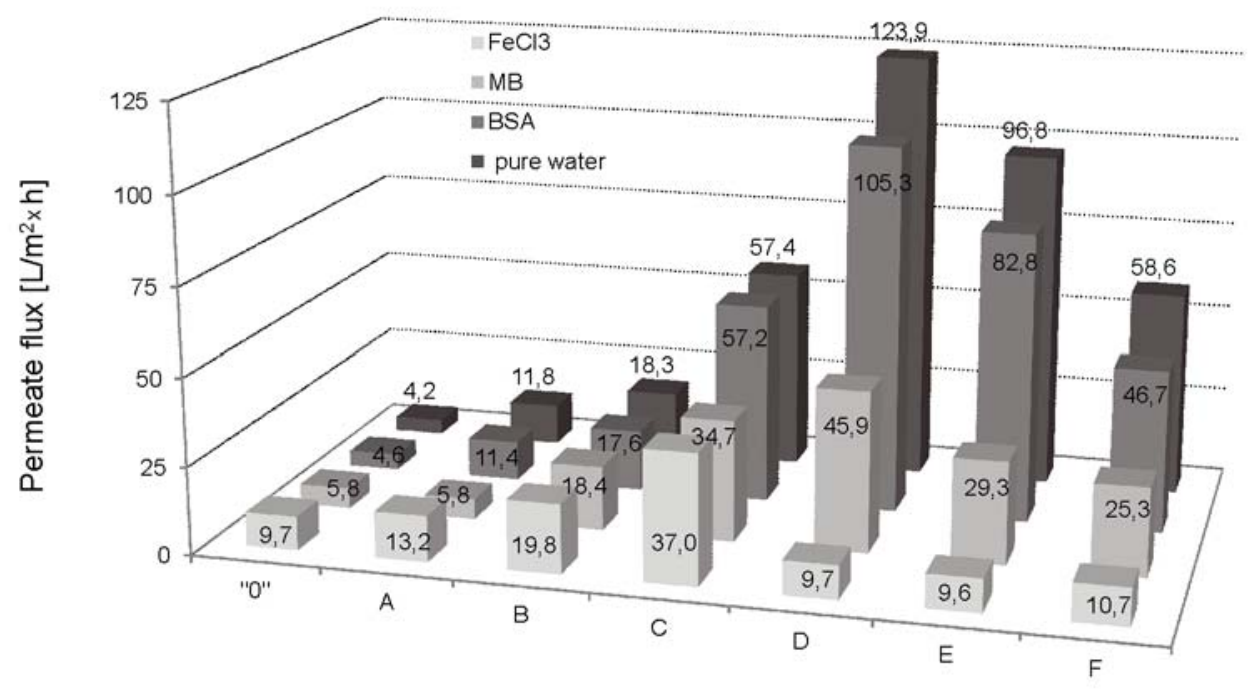

Figure 5. Volume permeate flux for $\mathrm{FeCl}_{3}, \mathrm{MB}$, BSA solutions (operating pressure of $0.2 \mathrm{MPa}$ ) 
is difficult for many reasons. First, the authors ${ }^{43}$ study completely different composite membranes in which the carrier layer is cellulose paper, while GO film is the skin layer. Moreover, the GO layer is responsible for the transport of the dyes in the described membranes. On the other hand, in our GO/CEL membranes, graphene oxide is dispersed, which makes it difficult to compare the results we obtained with the literature ${ }^{43}$. By studying the behavior of the membranes in the presence of $\mathrm{FeCl}_{3}$ solution, it was observed that iron (III) ions improve the volumetric permeate flux parameters for membranes " 0 ", $A$ and B. Higher GO concentrations in the GO/CEL composite deteriorates the membrane transport properties and decreases the flow values. The studies allow to conclude that high concentrations of GO (over 1\%) used as an addition in GO/CEL composite membranes adversely affect membrane performance, resulting in fouling. This phenomenon can be closely related to the electrostatic interactions between electro-negatively charged membrane and $\mathrm{Fe}^{3+}$ ions and the possibility of formation of coordination links between the functional groups of the membrane and the metal cations.

\section{CONCLUSIONS}

The paper describes the technique of obtaining GO/ CEL composite membranes by wet phase inversion method. The ionic liquid, 1-ethyl-3-methylimidazole acetate was used for dissolution of cellulose, as the best, recommended by authors of many publications ${ }^{54-55}$. In addition, cellulose regenerated with this method is more amorphous $^{56}$ than native cellulose and devoid of such low molecular weight compounds as lignin. The second component of the described composite was graphene oxide, which, in addition to the metal ion sorption properties, has antimicrobial properties ${ }^{24,45}$.

The paper presents results of investigations of physicochemical and transport properties of $\mathrm{GO} / \mathrm{CEL}$ composite membranes obtained from cellulose with graphene oxide addition. It was observed that GO affects the process of membrane formation, preventing them from washing out during coagulation, thereby increasing the mass per unit area. In addition, the use of $0.5 \sim 2 \%$ GO as an additive to the cellulose matrix increases the thickness of the resulting membranes, which lowers their density. Water sorption studies have shown that cellulose membranes with added GO absorb less water than pure cellulose membranes. The observed phenomenon may be due to a decrease in the hydrophilic properties of the GO/CEL composite membranes as a result of the formation of linkages between cellulose and graphene oxide functional groups. The results of specific permeate flux studies show that the GO addition facilitates the transport of water through the membranes. For GO/ CEL membranes, high flow rates $\left(\sim 124 \mathrm{~L} / \mathrm{m}^{2} \times \mathrm{h}\right)$ were obtained for cellulose matrix containing $3.8 \% \mathrm{w} / \mathrm{w}$ of GO. Studies have also shown that GO/CEL membranes do not sorb BSA particles on their surface, which prevents the unfavorable phenomenon of fouling, as confirmed by a specific permeate flux research.

It was shown that cellulose composite membranes with GO addition below $2 \% \mathrm{w} / \mathrm{w}$ feature adequate porosity, water sorption, good transport properties and protein retention, but without lowering the volume permeate flux. The technique of combining cellulose with graphene oxide described in the paper, and the properties of the resulting composite allowed to obtain a biomaterial which could find potential application in dialyzers.

\section{ACKNOWLEDGEMENTS}

The authors would like to thank M. Sieradzka, M.Sc. for the synthesis of GO.

\section{LITERATURE CITED}

1. Ramamoorthy, S.K., Skrifvars, M. \& Persson, A. (2015). A Review of Natural Fibers Used in Biocomposites: Plant, Animal and Regenerated Cellulose Fibers. Polym. Rev. 55, 107-162. DOI: 10.1080/15583724.2014.971124.

2. Yang, W., Fang, B. \& Tang, Y.Y. (2016). Fast and Accurate Vanishing Point Detection and Its Application in Inverse Perspective Mapping of Structured Road IEEE Trans. Syst. Man, Cybern. Syst. 1-12. DIO: 10.1109/TSMC.2016.2616490.

3. Wendler, F., Meister, F., Wawro, D., Wesolowska, E., Ciechańska, D., Saake, B., Puls, J., le Moigne, N. \& Navard, P. (2010). Polysaccharide blend fibres formed from $\mathrm{NaOH}, \mathrm{N}-$ -methylmorpholine-N-oxide and 1-Ethyl-3-methylimidazolium acetate. Fibres Text. East. Eur. 79, 21-30.

4. Pinkert, A., Marsh, K.N., Pang, S. \& Staiger, M.P. (2009) Ionic liquids and their interaction with cellulose. Chem. Rev. 109, 6712-6728. DOI:10.1021/cr9001947.

5. Lindman, B., Karlström, G. \& Stigsson L. (2010). On the mechanism of dissolution of cellulose. J. Mol. Liq. 156, 76-81. DOI: 10.1016/j.molliq.2010.04.016.

6. Fink, H.P., Weigel, P., Purz, H.J. \& Ganster, J. (2001). Structure formation of regenerated cellulose materials from NMMO-solutions. Prog. Polym. Sci. 26, 1473-1524. DOI: 10.1016/S0079-6700(01)00025-9.

7. Wang, S., Lu, A. \& Zhang, L. (2016). Recent advances in regenerated cellulose materials. Prog. Polym. Sci. 53, 169-206. DOI: 10.1016/j.progpolymsci.2015.07.003.

8. Swatloski, R.P., Holbrey, J.D. \& Rogers, R.D. (2003). Ionic liquids are not always green: hydrolysis of 1-butyl-3-methylimidazolium hexafluorophosphate. Green Chem. 5, 361. DOI: 10.1039/b304400a.

9. Gathergood, N., Garcia, M.T. \& Scammells, P.J. (2004). Biodegradable ionic liquids: Part I. Concept, preliminary targets and evaluation. Green Chem. 6, 166. DOI: 10.1039/b315270g.

10. Novoselov, N.P., Sashina, E.S., Kuz'mina, O.G. \& Troshenkova, S.V. (2007). Ionic liquids and their use for the dissolution of natural polymers. Russ. J. Gen. Chem. 77, 1395-1405. DOI: 10.1134/S1070363207080178.

11. Zhu, S., Wu, Y., Chen, Q., Yu, Z., Wang, C., Jin, S., Ding, Y. \& Wu, G. (2006). Dissolution of cellulose with ionic liquids and its application: a mini-review. Green Chem. 8, 325. DOI: $10.1039 / b 601395 c$.

12. Rambo, C.R., Recouvreux, D.O.S., Carminatti, C.A., Pitlovanciv, A.K., Antônio, R.V. \& Porto, L.M. (2008). Template assisted synthesis of porous nanofibrous cellulose membranes for tissue engineering. Mater. Sci. Eng. C. 28, 549-554. DOI: 10.1016/j.msec.2007.11.011.

13. Kuo, Y.N. \& Hong, J. (2005). A new method for cellulose membrane fabrication and the determination of its characteristics. J. Coll. Inter. Sci. 285, 232-238. DOI: 10.1016/j. jcis.2004.10.043.

14. Xiao, W., Yin, W., Xia, S. \& Ma, P. (2012). The study of factors affecting the enzymatic hydrolysis of cellulose after ionic liquid pretreatment. Carbohydr. Polym. 87, 2019-2023. DOI: 10.1016/j.carbpol.2011.10.012.

15. Zhao, H., Jones, C.L., Baker, G.A., Xia, S., Olubajo, O. \& Person, V.N. (2009). Regenerating cellulose from ionic 
liquids for an accelerated enzymatic hydrolysis. J. Biotechnol. 139, 47-54. DOI: 10.1016/j.jbiotec.2008.08.009.

16. Ślusarczyk, C., Fryczkowska, B., Sieradzka, M. \& Janicki, J. (2016). Small-angle X-ray scattering studies of pore structure in cellulose membranes. Acta Phys. Pol. A. 229-232. DOI: 10.12693/APhysPolA.129.229.

17. Östlund, Å., Idström, A., Olsson, C., Larsson, P.T. \& Nordstierna, L. (2013). Modification of crystallinity and pore size distribution in coagulated cellulose films. Cellulose 20 1657-1667. DOI: 10.1007/s10570-013-9982-7.

18. Fryczkowski, R., Gorczowska, M., Ślusarczyk, C., Fryczkowska, B. \& Janicki, J. (2013). The possibility of obtaining graphene/polymer composites from graphene oxide by a one step process. Compos. Sci. Technol. 80, 87-92. DOI: 10.1016/j. compscitech.2013.03.012.

19. Guerrero-Contreras, J. \& Caballero-Briones, F. (2015). Graphene oxide powders with different oxidation degree, prepared by synthesis variations of the Hummers method. Mater. Chem. Phys. 153, 209-220. DOI: 10.1016/j.matchemphys.2015.01.005.

20. Yoon, K.Y., An, S.J., Chen, Y., Lee, J.H., Bryant, S.L., Ruoff, R.S., Huh, C. \& Johnston, K.P. (2013). Graphene oxide nanoplatelet dispersions in concentrated $\mathrm{NaCl}$ and stabilization of oil/water emulsions. J. Coll. Inter. Sci. 403, 1-6. DOI: 10.1016/j.jcis.2013.03.012.

21. Texter, J. (2014). Graphene dispersions. Curr. Opin. Coll. Inter. Sci. 19, 163-174. DOI: 10.1016/j.cocis.2014.04.004.

22. Parades, J.I., Villar-Rodil, S., Martínez-Alonso, A. \& Tascón, J.M.D. (2008). Graphene oxide dispersions in organic solvents. Langmuir 24, 10560-10564. DOI: 10.1021/la801744a.

23. Sitko, R., Zawisza, B. \& Malicka, E. (2013). Graphene as a new sorbent in analytical chemistry. TrAC Trends Anal. Chem. 51, 33-43. DOI: 10.1016/j.trac.2013.05.011.

24. Musico, Y.L.F., Santos, C.M., Dalida, M.L.P. \& Rodrigues, D.F. (2014). Surface Modification of Membrane Filters Using Graphene and Graphene Oxide-Based Nanomaterials for Bacterial Inactivation and Removal. ACS Sustain. Chem. Eng. 2, 1559-1565. DOI: 10.1021/sc500044p.

25. Goh, K., Setiawan, L., Wei, L. Jiang, W., Wang, R. \& Chen, Y. (2013). Fabrication of novel functionalized multi-walled carbon nanotube immobilized hollow fiber membranes for enhanced performance in forward osmosis process. J. Memb. Sci. 446, 244-254. DOI: 10.1016/j.memsci.2013.06.022.

26. Das, R., Ali, M.E., Hamid, S.B.A., Ramakrishna, S., Chowdhury, Z.Z. (2014). Carbon nanotube membranes for water purification: A bright future in water desalination. Desalination 336, 97-109. DOI: 10.1016/j.desal.2013.12.026.

27. Hinds, B.J., Chopra, N., Rantell, T., Andrews, R., Gavalas, V. \& Bachas, L.G. (2004). Aligned multiwalled carbon nanotube membranes. Science. 303, 62-65. DOI: 10.1126/science.1092048.

28. Celik, E., Park, H., Choi, H. \& Choi, H. (2011). Carbon nanotube blended polyethersulfone membranes for fouling control in water treatment. Water Res. 45, 274-282. DOI: 10.1016/j.watres.2010.07.060.

29. Mahmoud, K.A., Mansoor, B., Mansour, A. \& Khraisheh, M. (2015). Functional graphene nanosheets: The next generation membranes for water desalination. Desalination 356, 208-225. DOI: 10.1016/j.desal.2014.10.022.

30. Han, Y., Xu, Z. \& Gao, C. (2013). Ultrathin graphene nanofiltration membrane for water purification. Adv. Funct. Mater. 23, 3693-3700. DOI: 10.1002/adfm.201202601.

31. Joshi, R.K., Alwarappan, S., Yoshimura, M, Sahajwalla, V. \& Nishina, Y. (2015). Graphene oxide: the new membrane material. Appl. Mater. Today 1-12. DOI: 10.1016/j. apmt.2015.06.002.

32. He, L., Dumée, L.F., Feng, C., Velleman, L., Reis, R., She, F., Gao, W. \& Kong, L. (2015). Promoted water transport across graphene oxide-poly(amide) thin film composite membranes and their antibacterial activity. Desalination 365, 126-135. DOI: 10.1016/j.desal.2015.02.032.
33. Park, M.J., Phuntsho, S., He, T., Nisola, G.M., Tijing, L.D., Li, X.M., Chen, G., Chung, W.J. \& Shon, H.K. (2015). Graphene oxide incorporated polysulfone substrate for the fabrication of flat-sheet thin-film composite forward osmosis membranes. J. Memb. Sci. 493, 496-507. DOI: 10.1016/j. memsci.2015.06.053.

34. Xia, S., Ni, M., Zhu, T., Zhao, Y. \& Li, N. (2015). Ultrathin graphene oxide nanosheet membranes with various d-spacing assembled using the pressure-assisted filtration method for removing natural organic matter. Desalination 371, 78-87. DOI: 10.1016/j.desal.2015.06.005.

35. Faria, A.F., Liu, C., Xie, M., Perreault, F., Nghiem, L.D., Ma, J. \& Elimelech, M. (2017). Thin-film composite forward osmosis membranes functionalized with graphene oxide-silver nanocomposites for biofouling control. J. Memb. Sci. 525, 146-156. DOI: 10.1016/j.memsci.2016.10.040.

36. Goh, P.S. \& Ismail, A.F. (2015). Graphene-based nanomaterial: The state-of-the-art material for cutting edge desalination technology. Desalination. 356, 115-128. DOI: 10.1016/j.desal.2014.10.001.

37. Nair, R.R., Wu, H.A., Jayaram, P.N., Grigorieva, I.V. \& Geim, A.K. (2012). Unimpeded Permeation of Water Through Helium-Leak-Tight Graphene-Based Membranes. Science 335, 442-444. DOI: 10.1126/science.1211694.

38. Bhadra, M., Roy, S. \& Mitra, S. (2016). Desalination across a graphene oxide membrane via direct contact membrane distillation. Desalination 378, 37-43. DOI: 10.1016/j. desal.2015.09.026.

39. Zhang, X., Yu, H., Yang, H., Wan, Y., Hu, H., Zhai, Z. \& Qin, J. (2015). Graphene oxide caged in cellulose microbeads for removal of malachite green dye from aqueous solution. J. Coll. Inter. Sci. 437, 277-282. DOI: 10.1016/j.jcis.2014.09.048.

40. Zhu, W., Li, W., He, Y. \& Duan, T. (2015). In-situ biopreparation of biocompatible bacterial cellulose/graphene oxide composites pellets. Appl. Surf. Sci. 338, 22-26. DOI: 10.1016/j.apsusc.2015.02.030.

41. Wan, C. \& Li, J. (2016). Graphene oxide/cellulose aerogels nanocomposite: Preparation, pyrolysis, and application for electromagnetic interference shielding. Carbohydr. Polym. 150, 172-179. DOI: 10.1016/j.carbpol.2016.05.051.

42. Rui-Hong, X., Peng-Gang, R., Jian, H., Fang, R., Lian-Zhen, R. \& Zhen-Feng, S. (2016). Preparation and properties of graphene oxide-regenerated cellulose/polyvinyl alcohol hydrogel with $\mathrm{pH}$-sensitive behavior. Carbohydr. Polym. 138, 222-228. DOI: 10.1016/j.carbpol.2015.11.042.

43. Liu, G., Ye, H., Li, A., Zhu, C., Jiang, H., Liu, Y., Han, K. \& Zhou, Y. (2016). Graphene oxide for high-efficiency separation membranes: Role of electrostatic interactions. Carbon N. Y. 110, 56-61. DOI: 10.1016/j.carbon.2016.09.005.

44. Huang, Q., Xu, M., Sun, R. \& Wang, X. (2016). Large scale preparation of graphene oxide/cellulose paper with improved mechanical performance and gas barrier properties by conventional papermaking method. Ind. Crops Prod. 85, 198-203. DOI: 10.1016/j.indcrop.2016.03.006.

45. Yang, X.N., Xue, D.D., Li, J.Y., Liu, M., Jia, S.R., Chu, L.Q., Wahid, F., Zhang, Y.M. \& Zhong, C. (2016). Improvement of antimicrobial activity of graphene oxide/bacterial cellulose nanocomposites through the electrostatic modification. Carbohydr. Polym. 136, 1152-1160. DOI: 10.1016/j.carbpol.2015.10.020.

46. Kafy, A., Akther, A., Shishir, M.I.R., Kim, H.C, Yun, Y. \& Kim, J. (2016). Cellulose nanocrystal/graphene oxide composite film as humidity sensor. Sensors Actuators, A Phys. 247, 221-226. DOI: 10.1016/j.sna.2016.05.045.

47. Kim, C.J., Khan, W., Kim, D.H., Cho, K.S. \& Park, S.Y. (2011). Graphene oxide/cellulose composite using NMMO monohydrate. Carbohydr. Polym. 86, 903-909. DOI: 10.1016/j. carbpol.2011.05.041.

48. Tang, L., Li, X., Du, D. \& He, C. (2012). Fabrication of multilayer films from regenerated cellulose and graphene 
oxide through layer-by-layer assembly. Prog. Nat. Sci. Mater. Int. 22, 341-346. DOI: 10.1016/j.pnsc.2012.06.005.

49. Cao, Y., Wu, J., Zhang, J., Li, H., Zhang, Y. \& He, J. (2009). Room temperature ionic liquids (RTILs): A new and versatile platform for cellulose processing and derivatization. Chem. Eng. J. 147, 13-21. DOI: 10.1016/j.cej.2008.11.011.

50. Hummers, W.S. \& Offeman, R.E. (1958). Preparation of Graphitic Oxide. J. Am. Chem. Soc. 80, 1339-1339. DOI: 10.1021/ja01539a017.

51. Fryczkowska, B., Sieradzka, M., Sarna, E., Fryczkowski, R. \& Janicki, J. (2015). Influence of a graphene oxide additive and the conditions of membrane formation on the morphology and separative properties of poly(vinylidene fluoride) membranes. J. Appl. Polym. Sci. 132, DOI: 10.1002/app.42789.

52. Zinadini, S., Zinatizadeh, A.A., Rahimi, M., Vatanpour, V. \& Zangeneh, H. (2014). Preparation of a novel antifouling mixed matrix PES membrane by embedding graphene oxide nanoplates. J. Memb. Sci. 453, 292-301. DOI: 10.1016/j.memsci.2013.10.070.

53. Wypych, G. (2012). Handbook of Polymers (2nd edition). Ontario, Canada: ChemTec Publishing.

54. Kosan, B., Michels, C. \& Meister, F. (2008). Dissolution and forming of cellulose with ionic liquids. Cellulose 15, 59-66. DOI: 10.1007/s10570-007-9160-x.

55. Gupta, K. M., Hu, Z. \& Jiang, J. (2011). Mechanistic understanding of interactions between cellulose and ionic liquids: A molecular simulation study. Polymer (Guildf) 52, 5904-5911. DOI: 10.1016/j.polymer.2011.10.035.

56. Xu, A., Guo, X. \& Xu, R. (2015). Understanding the dissolution of cellulose in 1-butyl-3-methylimidazolium acetate+DMAc solvent. Int. J. Biol. Macromol. 81, 1000-1004. DOI: 10.1016/j.ijbiomac.2015.09.058. 